\title{
Excepción preliminar planteada en el asunto referido a la obligación de negociar un acceso al océano Pacífico (Bolivia vs. Chile)
}

\author{
Gattas Abugattas*
}

\section{RESUMEN}

En la tramitación del proceso contencioso ante la Corte Internacional de Justicia (CIJ) iniciado por Bolivia contra Chile, referido a la obligación de negociar un acceso al océano Pacífico, este último Estado presentó una excepción preliminar respecto a la competencia de la CIJ. El artículo hace un breve análisis de la regulación de las excepciones preliminares en el Reglamento de la CIJ, resume los argumentos chilenos que sustentaron su objeción a la competencia de la CIJ, muestra los contraargumentos bolivianos y presenta tanto los argumentos como la decisión final de la CIJ. El trabajo termina con los comentarios del autor sobre la posición de las partes y la sentencia de la CIJ.

Palabras clave: Excepciones preliminares, Corte Internacional de Justicia (CIJ), obligación de negociar un acceso al océano Pacífico, Chile, Bolivia, Pacto de Bogotá, Tratado de Paz de 1904.

Preliminary Objection Lodged In The Obligation To Negotiate Access To The Pacific Ocean Case (Bolivia V. Chile)

\section{Abstract}

In the handling of the contentious proceedings before the International Court of Justice (ICJ) initiated by Bolivia against Chile, regarding the obligation to negotiate access to the Pacific Ocean, the latter State lodged a preliminary objection concerning the ICJ's jurisdiction. The paper makes a brief analysis of the preliminary objections' regulation in the Rules of the ICJ, summarizes the Chilean arguments that supported their objection to the ICJ's jurisdiction,

\footnotetext{
*Abogado por la Pontificia Universidad Católica del Perú (PUCP), máster en Diplomacia y Relaciones Internacionales por la Escuela Diplomática de Espańa y doctor en Derecho por la PUCP. Profesor ordinario asociado en el área de Derecho Internacional Público y Relaciones Internacionales en la PUCP. Correo electrónico: gabugattas@pucp.edu.pe
} 
shows Bolivian counterarguments and presents both the arguments and the final decision of the ICJ. The document ends with the author's comments on the position of the parties and the judgment of the ICJ.

Keywords: Preliminary objections, International Court of Justice (ICJ), obligation to negotiate access to the Pacific Ocean, Chile, Bolivia, Pact of Bogotá, 1904 Peace Treaty. 


\section{A modo de introducción: excepciones preliminares ante la Corte Internacional de Justicia}

El Reglamento de la Corte Internacional de Justicia (en adelante «la Corte» $\mathrm{o}$ «CIJ») establece que en la tramitación de un proceso contencioso se pueden presentar hasta seis procedimientos incidentales: medidas provisionales (reguladas en los artículos 73 a 78), excepciones preliminares (artículo 79), reconvención (artículo 80), intervención (artículos 81 a 86), remisión especial a la Corte (artículo 87) y desistimiento (artículos 88 y 89) (Acosta, 1995, pp. 142-ss; Abi-Saab, 1967).

En ese sentido, lo primero que se puede concluir es que las excepciones preliminares se tramitan como un procedimiento incidental; es decir, tienen prioridad frente al asunto de fondo que generó la controversia (Pastor Ridruejo, 1967, p. 226). Sin embargo, para entender mejor qué es una excepción preliminar, quisiera citar lo señalado por Kolb:

A Preliminary Objection is the procedural means by which a party to a case (normally the respondent) can rise objections to jurisdiction or admissibility. In French it is called an exception rather than an 'objection' because it carves out an 'exception' to the substantive trial of the action, asking the Court to deal whit it as a matter of priority. [...]

Thus, according to the Dictionnaire de droit international public, a preliminary objection is 'a legal argument raised in the course of the first phase of a case for the purpose of having the tribunal decide a preliminary question before examining the substantive issues: most often, the purpose of the objection is to prevent the tribunal from ever addressing the substantive issues' (our translation) (Kolb, 2013, p. 224).

En este orden de ideas, se puede apreciar que las excepciones preliminares buscan cuestionar la competencia de la Corte, la admisibilidad de la solicitud para iniciar un proceso contencioso ante ella o, incluso, como lo señala el Reglamento de la $\mathrm{CIJ}$, cualquier otra materia que requiera un pronunciamiento previo de la Corte, antes de analizar el fondo de un asunto. Así, el primer párrafo del artículo 79 del citado Reglamento establece:

Artículo 79

1. Cualquier excepción preliminar a la competencia de la Corte o a la admisibilidad de la solicitud, o cualquier otra excepción sobre la cual el demandado pide que la Corte se pronuncie antes de continuar el procedimiento sobre el fondo, deberá ser presentada por escrito.

Ante esta regulación, cabría preguntarse cuál o cuáles podrían ser esas otras excepciones respecto de las cuales el demandado estaría facultad a pedir que la Corte se pronuncie antes de analizar el asunto de fondo de una controversia. Sin embargo, en 
lugar de hacer un ejercicio teórico que me lleve a la determinación de la respuesta a esa pregunta, prefiero recordar lo señalado por Kolb:

This means that an objection can be made to jurisdiction, admissibility, or some other category not identified in the Article, provided that it is preliminary (that is, prior to the merits). [...] However, it should be added that the Court's practice does not indicate that it feels any need to create a further category of Preliminary Objection in addition to jurisdiction and admissibility. It is therefore possible to say that, until now, all the Preliminary Objections that have been raised before the Court have been, at least by implication, objections either to jurisdiction or to admissibility. [...] The Article does, however, leave the Court an obvious element of flexibility for the future (Kolb, 2013, p. 225).

Ahora bien, en cuanto a la determinación de los sujetos capacitados para presentar una excepción preliminar, sobre la base de lo establecido en el primer párrafo del artículo 79 del Reglamento de la CIJ, se puede concluir que cualquier parte en el proceso está facultada para iniciar el trámite de una excepción preliminar:

Artículo 79

1. Cualquier excepción a la competencia de la Corte o a la admisibilidad de la solicitud, o cualquier otra excepción sobre la cual el demandado pide que la Corte se pronuncie antes de continuar el procedimiento sobre el fondo, deberá ser presentada por escrito lo antes posible, y a más tardar en el plazo de tres meses a partir de la presentación de la memoria. Cualquier excepción opuesta por una parte que no sea el demandado deberá depositarse dentro del plazo fijado para el depósito del primer alegato escrito de esa parte.

En ese sentido, si bien es cierto que lo usual será que quien presente la excepción preliminar sea el demandado, puede llegar a ser posible, en situaciones muy particulares, que el propio Estado demandante presente una excepción preliminar. Además, cualquier parte que haya presentado una o varias excepciones preliminares, está facultada a retirarlas todas o algunas de ellas (Kolb, 2013, pp. 229-230).

Por otro lado, hay que tomar en cuenta que solo los terceros Estados que participen en el proceso contencioso por vía de un procedimiento incidental; es decir, que no son demandantes ni demandados, pero que tienen un interés jurídico en el proceso y cuya intervención en él se produce en virtud de los artículos 62 o 63 del Estatuto de la CIJ; podrían, eventualmente, presentar excepciones preliminares (Kolb, 2013, pp. 230-231) $)^{1}$.

\footnotetext{
Recuérdese que los artículos 62 y 63 del Estatuto de la Corte Internacional de Justicia establecen: «Artículo 62

Si un Estado considerare que tiene un interés de orden jurídico que puede ser afectado por la decisión del litigio, podrá pedir a la Corte que le permita intervenir.

La Corte decidirá con respecto a dicha petición.
} 
En todo caso, si, como es usual, el demandado es quien presenta la excepción preliminar, en la tramitación de dicha excepción hay que tomar en cuenta que se invertirán los roles en el proceso: el demandado sería el demandante en el procedimiento incidental en el que se discuta la excepción preliminar por él planteada, teniendo por tanto la carga de la prueba, y el demandante original sería ahora el demandado en el procedimiento incidental.

Al margen de todo lo anterior, no se puede dejar de mencionar que, ingresada una solicitud para iniciar un proceso contencioso, la Corte puede, de oficio, pronunciarse sobre cuestiones referidas a su competencia o a la admisibilidad de tal solicitud. Esta capacidad de la Corte está regulada en los párrafos 2 y 3 del artículo 79 de su Reglamento, en el que se establece que:

Artículo 79

[...]

2. No obstante lo dispuesto en el párrafo 1, una vez presentada la solicitud y después de que el Presidente se haya reunido y celebrado consultas con las partes, la Corte podrá decidir la necesidad de pronunciarse sobre cualquier cuestión de competencia y admisibilidad por separado.

3. Si la Corte así lo decide, las partes presentarán los alegatos relativos a la competencia y la admisibilidad en los plazos fijados por la Corte y en el orden por ella establecido, no obstante lo dispuesto en el párrafo 1 del Artículo $45^{2}$.

Por otro lado, en cuanto al plazo para presentar una excepción preliminar, hay que recordar lo seńalado en el párrafo 1 del artículo 79 del Reglamento de la CIJ:

Artículo 79

1. Cualquier excepción a la competencia de la Corte o a la admisibilidad de la solicitud, o cualquier otra excepción sobre la cual el demandado pide que la Corte se pronuncie antes de continuar el procedimiento sobre el fondo, deberá ser presentada por escrito lo antes posible, y a más tardar en el plazo de tres meses a partir de la presentación de la memoria. Cualquier excepción opuesta por una parte que no sea el demandado deberá depositarse dentro del plazo fijado para el depósito del primer alegato escrito de esa parte.

Artículo 63

Cuando se trate de la interpretación de una convención en la cual sean partes otros Estados además de las partes en litigio, el Secretario notificará inmediatamente a todos los Estados interesados.

Todo Estado así notificado tendrá derecho a intervenir en el proceso; pero si ejerce ese derecho, la interpretación contenida en el fallo será igualmente obligatoria para él».

2 El párrafo 1 del artículo 45 del Reglamento de la Corte Internacional de Justicia establece: «Artículo 45

1. En un procedimiento incoado mediante una solicitud, los alegatos escritos consistirán, por su orden, en una memoria del demandante y en una contramemoria del demandado». 
Como se puede apreciar, la idea que está detrás de lo señalado en el primer párrafo del artículo 79 es que las excepciones preliminares se presenten siempre lo antes posible y, en el peor de los casos, a más tardar tres meses contados a partir de la presentación de la memoria o, para quienes no son el demandado, en el mismo momento de la presentación de su primer alegato escrito. $\mathrm{Al}$ respecto hay que recordar dos cosas: primero, la tramitación de una excepción preliminar detiene el proceso en lo que respecta al análisis del fondo de la controversia, en ese sentido, entre más rápido se resuelva la excepción preliminar, más rápido se continuará con el proceso, evitando que la presentación de excepciones preliminares se constituya en una mera estrategia para ganar tiempo.

En segundo lugar, hay que recordar que la redacción original de este primer párrafo establecía que las excepciones preliminares debían presentarse «dentro del plazo fijado para el depósito de la contramemoria». De esta manera, las excepciones se podían presentar con bastante celeridad o, incluso, el mismo día en que se debía presentar la contramemoria, dilatando en exceso el proceso contencioso. Por ello, dicha fórmula original, adoptada el 14 de abril de 1978, fue evidentemente mejorada con la actual determinación del plazo, que se hizo a través de una enmienda al Reglamento de la CIJ que entró en vigor el 01 de febrero de 2001, pero solo para aquellos casos que fueron sometidos a la Corte luego de esa fecha.

Finalmente, en cuanto a las formalidades referidas a la tramitación de las excepciones preliminares, hay que tomar en cuenta, por un lado, aquellas ya señaladas líneas arriba: primero, las que se desprenden del párrafo 1 del citado artículo 79, en el que se determina quién puede presentar una excepción preliminar, se exige que tal presentación se haga por escrito y se fija el plazo para hacerlo; y, segundo, las que se desprenden de los párrafos 2 y 3 del mismo artículo, en los que se regula la actuación de oficio de la Corte sobre cualquier cuestión de competencia o admisibilidad.

Luego, por otro lado, hay que tomar en cuenta también el resto de formalidades referidas a la tramitación de las excepciones preliminares que están detalladas en los siguientes párrafos del artículo 79 del Reglamento de la CIJ:

«Artículo 79

[...]

4. El escrito mediante el cual se plantee la excepción preliminar contendrá una exposición de los hechos y fundamentos de derecho en que se basa la excepción, las conclusiones y una lista de los documentos en apoyo; mencionará los medios de prueba que la parte se proponga producir. Se acompañarán copias de los documentos en apoyo.

5. Al recibo por la Secretaría de la Corte del escrito planteando la excepción preliminar se suspenderá el procedimiento sobre el fondo y la Corte, o si no estuviese reunida el Presidente, fijará un plazo dentro del cual la otra parte 
podrá presentar una declaración escrita con sus observaciones y conclusiones; se acompańarán los documentos en apoyo y se indicarán los medios de prueba que se proponga producir.

6. Salvo decisión contraria de la Corte, la continuación del procedimiento sobre la excepción será oral.

7. Las exposiciones de hechos y de fundamentos de derecho referidas en los párrafos 4 y 5 de este Artículo y los alegatos y medios de prueba presentados durante las vistas previstas en el párrafo 6 se limitarán a los puntos a que se refiera la excepción.

8. A fin de que la Corte pueda pronunciarse sobre su competencia en la fase preliminar del procedimiento, la Corte podrá, cuando sea necesario, invitar a las partes a debatir todo punto de hecho y de derecho y a producir todo medio de prueba que se relacione con la cuestión.

9. La Corte, oídas las partes, decidirá por medio de un fallo, en el que aceptará o rechazará la excepción o declarará que la excepción no tiene, en las circunstancias del caso, un carácter exclusivamente preliminar. Si la Corte rechazara la excepción o declarara que no tiene un carácter exclusivamente preliminar, fijará los plazos para la continuación del procedimiento.

10. La Corte dará efecto a todo acuerdo entre las partes encaminado a que una excepción planteada en virtud del párrafo 1 de este Artículo sea resuelta al examinar el fondo.

Ahora bien, de todo este conjunto de formalidades referidas a la tramitación de las excepciones preliminares, me interesa destacar las opciones que tiene la Corte frente a las excepciones preliminares. En otras palabras, quisiera resumir las alternativas de la Corte al momento de resolver excepciones preliminares, en virtud de lo señalado en el citado párrafo 9 del artículo 79 del Reglamento.

Así, frente al planteamiento de excepciones preliminares, la Corte, luego de tomar en cuenta la posición de las partes en el litigio, puede optar por una de las siguientes cuatro alternativas ${ }^{3}$ :

1. Rechazar todas las excepciones preliminares presentadas. En este supuesto, el procedimiento sobre el fondo, inicialmente suspendido en virtud de lo señalado en el párrafo 5 del citado artículo 79, continuaría, debiendo, la Corte, fijar los nuevos plazos para ello.

2. Aceptar todas las excepciones preliminares presentadas, en cuyo caso el procedimiento sobre el fondo terminaría.

3. Si fueran varias excepciones preliminares, podría aceptar algunas y rechazar otras; o, si fuera una sola excepción preliminar, pero que solamente objeta de manera parcial la competencia de la Corte o la admisibilidad de la solicitud

\footnotetext{
3 Un desarrollo más detallado de las alternativas que se mencionan se puede encontrar en: Kolb, 2013, pp. 236237 y $240-246$.
} 
de inicio del proceso contencioso, podría aceptarla. En ambos supuestos, el procedimiento sobre el fondo continuaría, pero se habría limitado el alcance de la competencia de la Corte o el alcance de la admisibilidad de la solicitud.

4. Finalmente, la Corte también puede considerar que la excepción preliminar no tiene, en las circunstancias del caso, un carácter exclusivamente preliminar. En este supuesto, el procedimiento sobre el fondo continuaría, con los plazos que para tal efecto determine la Corte, y la decisión sobre la excepción preliminar se conocería junto con la decisión sobre el fondo del asunto.

Para terminar este punto, se debe considerar que, cualquiera que sea la decisión tomada por la Corte frente a una excepción preliminar, la regla general es que dicha decisión tenga el efecto de cosa juzgada. Esto significa que la decisión de la Corte no puede ser apelada, es decir, es una decisión definitiva (Acosta, 1995, pp. 148)4.

\section{Excepción preliminar planteada por Chile}

El 24 de abril de 2013 el Estado Plurinacional de Bolivia presentó ante la Corte Internacional de Justicia una solicitud para iniciar un proceso contencioso contra la República de Chile, referido a la obligación de esta última de negociar un acceso al océano Pacífico en favor de Bolivia.

El 18 de junio de 2013 la Corte fijó los plazos para la presentación de la memoria y de la contramemoria. Así, a Bolivia se le otorgó un plazo que vencía el 17 de abril de 2014 para presentar su memoria, mientras que a Chile se le otorgó un plazo que vencía el 18 de febrero de 2015 para presentar su contramemoria.

Bolivia, dos días antes del vencimiento del plazo, el 15 de abril de 2014, presentó su memoria. En ese sentido, de acuerdo con lo establecido en el párrafo 1 del artículo 79 del Reglamento de la CIJ, Chile podía presentar excepciones preliminares, a más tardar, el 15 de julio de 2014, es decir, tres meses después de presentada la memoria. En efecto, el 15 de julio de 2014 Chile presentó una excepción preliminar, referida a la falta de competencia de la Corte para conocer el asunto planteado por Bolivia.

El mismo 15 de julio de 2014, la Corte otorgó a Bolivia un plazo que vencía el 14 de noviembre de ese mismo año, para que presente una declaración escrita con sus observaciones y conclusiones en torno a la excepción preliminar presentada por Chile. Bolivia presentó dicha declaración escrita el 07 de noviembre de 2014.

Teniendo la excepción preliminar presentada por escrito por Chile y la declaración escrita presentada por Bolivia en torno a dicha excepción, en atención a lo señalado

\footnotetext{
4 Sin embargo, Kolb, haciendo una crítica a la Corte, nos recuerda que esta 'regla general' no siempre se ha aplicado (2013, pp. 237-240).
} 
en el párrafo 6 del artículo 79 del Reglamento de la CIJ, la continuación del procedimiento sobre la excepción preliminar fue oral. Así, entre el 04 y el 08 de mayo de 2015 se llevaron a cabo audiencias orales sobre la citada excepción. El 04 de mayo Chile, al haber planteado la excepción preliminar, fue el primero en presentar sus alegatos; el 06 de mayo Bolivia presentó los suyos; el 07 de mayo tuvo lugar la segunda fase de los alegatos de Chile y el 08 de mayo la segunda fase de los alegatos de Bolivia.

En su memoria, Bolivia solicitó a la Corte:

[...] que juzgue y declare que:

(a) Chile tiene la obligación de negociar con Bolivia en orden a alcanzar un acuerdo que otorgue a Bolivia un acceso completamente soberanos al Océano Pacífico,

(b) Chile ha violado dicha obligación,

(c) Chile debe llevar a cabo dicha obligación de buena fe, formal y prontamente, dentro de un tiempo razonable y en forma efectiva (CIJ, 2015a, p. 8, párr. 12; CIJ, 2015b, p. 35).

Cuando Chile presentó su excepción preliminar, solicitó a la Corte que declare que el asunto planteado por Bolivia estaba fuera de su jurisdicción. Los argumentos presentados por Chile tanto en el escrito en el que formula la excepción preliminar como en sus alegatos orales, se resumirán en los párrafos siguientes, tomando como referencia lo señalado por la Corte en la sentencia que puso fin a este procedimiento incidental.

En efecto, en la sentencia de la Corte que resuelve la excepción preliminar, se resume de manera clara la posición chilena. Así, la Corte señala que:

22. En su excepción preliminar, Chile reclama que, conforme al artículo VI del Pacto de Bogotá, la Corte carece de jurisdicción bajo el artículo XXXI del Pacto de Bogotá para decidir respecto de la disputa presentada por Bolivia ${ }^{5}$. Chile sostiene que las

5 Recuérdese que el Tratado Americano de Soluciones Pacíficas, más conocido como Pacto de Bogotá, establece lo siguiente:

"Artículo XXXI

De conformidad con el inciso $2^{\circ}$ del artículo 36 del Estatuto de la Corte Internacional de Justicia, las Altas Partes Contratantes declaran que reconocen respecto a cualquier otro Estado Americano como obligatoria ipso facto, sin necesidad de ningún convenio especial mientras esté vigente el presente Tratado, la jurisdicción de la expresada Corte en todas las controversias de orden jurídico que surjan entre ellas y que versen sobre:

a) La interpretación de un Tratado;

b) Cualquier cuestión de Derecho Internacional;

c) La existencia de todo hecho que, si fuere establecido, constituiría la violación de una obligación internacional;

d) La naturaleza o extensión de la reparación que ha de hacerse por el quebrantamiento de una obligación internacional».

Sin embargo, en el mismo Pacto de Bogotá se establece que:

«Artículo VI

Tampoco podrán aplicarse dichos procedimientos [refiriéndose a los procedimientos pacíficos de solución de controversias regulados en el Pacto] a los asuntos ya resueltos por arreglo de las partes, o por laudo arbitral, o por sentencia de un tribunal internacional, o que se hallen regidos por acuerdos o tratados en vigencia en la fecha de la celebración del presente Pacto» (agregado propio). 
materias en cuestión en el presente caso son la de la soberanía territorial y el carácter del acceso de Bolivia al Océano Pacífico. Refiriéndose al artículo VI del Pacto de Bogotá, argumenta que estas materias fueron resueltas por acuerdo en el Tratado de Paz de 1904 y que siguen siendo regidas por ese Tratado, el que estaba en vigor al tiempo de conclusión del Pacto de Bogotá. De acuerdo a Chile, los varios «acuerdos, práctica diplomática y [...] declaraciones» invocadas por Bolivia (ver párrafo 19 anterior) conciernen «en lo sustancial a las mismas materias resueltas en y regidas por el Tratado [de Paz de 1904]».

$[\ldots]$

29. [...] En consecuencia, Chile sostiene que la demanda boliviana busca «la revisión del acuerdo alcanzado en 1904 relativo a soberanía territorial y al carácter del acceso al mar de Bolivia».

$[\ldots]$

41. En opinión de Chile, el artículo VI del Pacto de Bogotá excluye indudablemente la presente disputa entre las partes de la jurisdicción de la Corte. Chile sostiene que el propósito del artículo VI del Pacto de Bogotá era el de excluir la posibilidad de utilizar los mecanismos de solución de controversias del Pacto, en particular los medios judiciales, "con el propósito de reabrir asuntos que ya estaban resueltos entre las partes del Pacto, debido a que ellos habían sido objeto de un decisión judicial internacional o de un tratado» (CIJ, 2015a: 11, párr. 22; 13, párr. 29, 17, párr. 41; CIJ, 2015b: $38-39,41$ y 45$)^{6}$.

Adicionalmente, la Corte recuerda que:

42. Chile sostiene que debe hacerse una distinción entre las dos partes del artículo VI y argumenta que un asunto está «resuelto» por un acuerdo si es que este se encuentra solucionado por dicho acuerdo, mientras que una materia se encuentra «regida» por un tratado si el tratado regula la relación entre las partes en relación a dicha materia. En el presente caso, Chile concluye que la soberanía territorial y el carácter del acceso de Bolivia al Océano Pacífico son materias ambas «resueltas» y «regidas» por el Tratado de Paz de 1904 (CIJ, 2015a, p. 17, párr. 42; CIJ, 2015b, p. 45).

En ese sentido, Chile se tomó su tiempo para explicar el alcance del Tratado de Paz de 1904 (CIJ, 2015a, p. 17, párr. 43-45); y, como señala la Corte:

46. Chile, por tanto, concluye que los términos del Tratado de Paz de 1904 no dejan lugar a duda que la «soberanía territorial» y «el carácter del acceso de Bolivia al Océano Pacífico» son asuntos resueltos y regidos por el Tratado (CIJ, 2015a, p. 17, párr. 46; CIJ, 2015b, p. 45).

6 Citando a: CIJ, 2007, p. 858, párr. 77. 


\section{Respuesta dada por el Estado Plurinacional de Bolivia}

Como ha sido explicado en el primer punto de este trabajo, si bien Bolivia es el Estado que inició el proceso contencioso ante la Corte Internacional de Justicia, en la tramitación de las excepciones preliminares se invierten los roles en el proceso. En ese sentido, Chile, que presentó la excepción preliminar, se convierte en el demandante en la tramitación del procedimiento incidental y Bolivia, si bien es el Estado originalmente demandante, se convierte en demandado en la tramitación de la excepción preliminar. Así, una vez presentados los argumentos chilenos para objetar la competencia de la Corte en este proceso contencioso, a Bolivia le correspondió responder a dichos argumentos.

Ahora bien, para entender mejor la respuesta dada por Bolivia, considero prudente recordar dos puntos importantes. En primer lugar, hay que tener presente que el 20 de octubre de 1904 Chile y Bolivia firmaron el Tratado de Paz y Amistad que terminó con la Guerra del Pacífico entre ambos Estados. Líneas arriba me he referido a ese acuerdo llamándolo «Tratado de Paz de 1904», como usualmente se le conoce, y de esa manera me seguiré refiriendo a él más adelante.

Dicho Tratado de Paz de 1904 entró en vigor el 10 de marzo de 1905 y, como lo recuerda la Corte, en virtud de él:

[...] la totalidad del territorio costero boliviano se transformó en chileno y a Bolivia le fue concedido un derecho de libre tránsito comercial a través de puertos chilenos (CIJ, 2015a, p. 9, párr. 16; CIJ, 2015b, p. 36).

En segundo lugar, es importante recordar que el 30 de abril de 1948 se adoptó el Tratado Americano de Soluciones Pacíficas, al que me he referido como «Pacto de Bogotá», nombre que suele recibir en atención a que dicha adopción se llevó a cabo en la capital de Colombia. En este Tratado se reafirma la obligación de las partes de resolver sus controversias internacionales por medios pacíficos y se establecen una serie de procedimientos de solución pacífica de controversias a los que los Estados parte podrán recurrir. Este Tratado es la base para sustentar la competencia de la Corte.

En efecto, el artículo XXXI del Pacto de Bogotá, del que son Estados parte tanto Bolivia como Chile, estipula que:

\section{Artículo XXXI}

De conformidad con el inciso $2^{\circ}$ del artículo 36 del Estatuto de la Corte Internacional de Justicia, las Altas Partes Contratantes declaran que reconocen respecto a cualquier otro Estado Americano como obligatoria ipso facto, sin necesidad de ningún convenio especial mientras esté vigente el presente Tratado, la jurisdicción de la expresada Corte en todas las controversias de orden jurídico que surjan entre ellas y que versen sobre: 
a) La interpretación de un Tratado;

b) Cualquier cuestión de Derecho Internacional;

c) La existencia de todo hecho que, si fuere establecido, constituiría la violación de una obligación internacional;

d) La naturaleza o extensión de la reparación que ha de hacerse por el quebrantamiento de una obligación internacional.

Sin embargo, la posibilidad de recurrir a los procedimientos de solución pacífica de controversias establecidos en el Pacto de Bogotá, entre ellos, el proceso contencioso que se lleva a cabo en el marco de la Corte Internacional de Justicia, tiene una serie de límites. En la tramitación de la excepción preliminar que se viene estudiando, es relevante el límite establecido en el artículo VI de dicho Pacto, que señala:

\section{Artículo VI}

Tampoco podrán aplicarse dichos procedimientos a los asuntos ya resueltos por arreglo de las partes, o por laudo arbitral, o por sentencia de un tribunal internacional, o que se hallen regidos por acuerdos o tratados en vigencia en la fecha de la celebración del presente Pacto (CIJ, 2015a, p. 11, párr. 21; CIJ, 2015b, p. 38) 7 .

Teniendo presente lo señalado hasta aquí, se pueden entender mejor los argumentos bolivianos esgrimidos para convencer a la Corte de desestimar la excepción preliminar planteada por Chile. Recuérdese que Bolivia, en su memoria, solicitó a la Corte:

[...] que juzgue y declare que:

(a) Chile tiene la obligación de negociar con Bolivia en orden a alcanzar un acuerdo que otorgue a Bolivia un acceso completamente soberanos al Océano Pacífico,

(b) Chile ha violado dicha obligación,

(c) Chile debe llevar a cabo dicha obligación de buena fe, formal y prontamente, dentro de un tiempo razonable y en forma efectiva (CIJ, 2015a, p. 8, párr. 12; CIJ, 2015b, p. 35).

\section{Como recuerda la Corte:}

19. En orden a fundar la existencia de la presenta obligación de negociar y su incumplimiento, Bolivia se refiere a «acuerdos, práctica diplomática y a una serie de declaraciones atribuibles a los más altos representantes de [Chile]». De acuerdo a Bolivia, la

\footnotetext{
7 Debe entenderse que cuando el artículo VI se refiere a la fecha de celebración del Pacto, se está considerando que tal fecha es el 30 de abril de 1948, día en que se adoptó este Tratado. Esta ha sido la interpretación que se le da a este artículo. En ese sentido, si bien el empleo de los términos «celebración» y «adopción» no se ajusta a lo que hoy en día prescribe la Convención de Viena de 1969 sobre el Derecho de los Tratados, hay que considerar que en 1948 no existía esta Convención y, por tanto, en atención a la práctica de aquella época, se puede admitir cierta flexibilidad en el uso de tales términos.

Un dato interesante sobre el artículo VI del Pacto de Bogotá, es que Bolivia presentó una reserva referida a la aplicación de dicho artículo. Chile, por su parte, objetó dicha reserva. Sin embargo, días antes de la presentación de la demanda ante la CIJ, Bolivia retiró la reserva al artículo VI del Pacto de Bogotá, ante lo que Chile, como seńala la Corte, declaró que «el retiro de la reserva al Pacto de Bogotá por parte de Bolivia hizo que dicho pacto entrase en vigor entre las Partes».
} 
mayor parte de estos eventos tuvieron lugar entre la conclusión del Tratado de Paz de 1904 y 2012 (CIJ, 2015a, p. 10, párr. 19; CIJ, 2015b, p. 37).

En ese sentido, según precisa la Corte:

23. La respuesta de Bolivia es que la excepción preliminar de Chile es «manifiestamente infundada» ya que «malinterpreta el objeto de la controversia» entre las Partes. Bolivia sostiene que el objeto de la controversia [se refiere a] la existencia e incumplimiento de una obligación por parte de Chile de negociar de buena fe con Bolivia un acceso soberano al Océano Pacífico. Señala que esta obligación existe independientemente del Tratado de Paz de 1904. Consecuentemente, Bolivia afirma que las materias en disputa no están resueltas ni regidas por ese Tratado, conforme a los términos del artículo VI del Pacto de Bogotá, y que la Corte tiene por ende jurisdicción conforme al artículo XXXI (CIJ, 2015a, p. 11 párr. 23; CIJ, 2015b, p. 39) ${ }^{8}$.

Bolivia afirma que en tanto que el asunto materia de la controversia no fue resuelto por el Tratado de Paz de 1904, ambas partes acordaron negociar un acceso soberano al océano Pacífico, independientemente de lo regulado en dicho Tratado de Paz (CIJ, 2015a, p. 18, párr. 47; CIJ, 2015b, p. 46). Además, como señala la Corte:

47. [...] Bolivia sostiene que las Partes se encontraban negociando este asunto pendiente hasta el 2011, cuando Chile supuestamente habría renegado de su obligación de negociar. Sostiene además que Chile debería cumplir con su obligación de negociar el acceso soberano de Bolivia al Océano Pacífico y que el Tratado de Paz de 1904 no puede proveer una base razonable para que Chile invoque el artículo VI del Pacto de Bogotá como un obstáculo a la jurisdicción de la Corte (CIJ, 2015a, p. 18, párr. 47; CIJ, 2015b, p. 46).

Por otro lado, Bolivia acepta la descripción de la finalidad del artículo VI del Pacto de Bogotá hecha Chile y reseñada por la Corte en el párrafo 41 citado líneas arriba. Sin embargo, considera que la interpretación chilena de dicho artículo es excesivamente amplia (CIJ, 2015a, p. 18, párr. 48). Por lo demás:

49. Bolivia afirma que, incluso si la interpretación de Chile sobre las dos partes del artículo VI fuera reconocida, la objeción aún fracasaría debido a que el Tratado de Paz de 1904 no podría haber resuelto una disputa que no existía en 1904 y debido a que no puede regir asuntos tales como los presentados por Bolivia, los cuales no fueron incluidos dentro de los términos de dicho Tratado. Bolivia sostiene que, a través de la tergiversación de su demanda como una relativa a «soberanía territorial y al carácter del acceso de Bolivia al mar» en vez de como es descrita en su Solicitud y Memoria, concretamente, «la existencia y violación de una obligación de negociar un acceso soberano al Océano Pacífico acordado por Chile», Chile erróneamente concluye que los asuntos en disputa son asuntos «resueltos y regidos por el Tratado de Paz de

8 La modificación introducida en la traducción es propia. 
1904» y que Bolivia simplemente está buscando «revisar o anular» dicho Tratado (CIJ, 2015a, p. 18, párr. 99; CIJ, 2015b, p. 46-47).

Finalmente, asumiendo la eventualidad de que la Corte entienda el objeto de la controversia en los términos descritos por Chile, es decir, que la controversia se refiere a la soberanía territorial y al carácter del acceso de Bolivia al mar, y no reconozca los argumentos bolivianos en el sentido de que la controversia se refiere al surgimiento posterior al Tratado de Paz de 1904 de una obligación que, además de existir, habría sido incumplida por Chile:

52. [...] Subsidiariamente, Bolivia alega que si la Corte analiza la excepción de Chile en base a la caracterización del objeto de la disputa que Chile realiza, la objeción equivaldría a un rechazo del caso boliviano en sus méritos y, por tanto, no tendría un carácter exclusivamente preliminar (CIJ, 2015a, p. 19, párr. 52; CIJ, 2015b, p. 47).

Sin embargo, debo precisar que esta alegación subsidiaria de Bolivia finalmente quedó sin objeto, pues, como precisaré más adelante, la Corte Internacional de Justicia no aceptó la caracterización de la finalidad de la demanda boliviana en los términos planteados por Chile.

\section{Decisión de la Corte Internacional de Justicia}

Dados los argumentos planteados por Chile sobre lo que considera el "verdadero» objeto de la disputa y los contraargumentos bolivianos al respecto, la Corte tuvo la necesidad de determinar primero lo que, para ella, es la finalidad de la demanda de Bolivia. Sobre esto, la Corte señaló lo siguiente:

24. La esencia de la excepción preliminar de Chile es que el asunto objeto del reclamo boliviano cae dentro del artículo VI del Pacto de Bogotá. La Corte observa, sin embargo, que el asunto que Chile considera que está excluido de la jurisdicción de la Corte en virtud del artículo VI (ver párrafo 22 supra) no corresponde al asunto objeto de la disputa descrito por Bolivia (ver párrafo 23 supra). Por consiguiente, es necesario que la Corte primero establezca sus propios puntos de vista sobre el asunto objeto de la disputa y que posteriormente llegue a sus propias conclusiones. La Corte entonces va a tratar ahora la pregunta sobre si los asuntos en disputa son asuntos «resueltos» o «regidos» por el Tratado de Paz de 1904 (CIJ, 2015a, p. 12, párr. 24; CIJ, 2015b, p. 39).

Así, en primer lugar, la Corte precisó que:

31. [...] La Solicitud no invoca el Tratado de Paz de 1904 como una fuente de derechos u obligaciones para ninguna de las Partes y tampoco pide a la Corte pronunciarse sobre el estatus legal de ese Tratado. Por lo tanto, la Solicitud presenta una disputa sobre la existencia de una obligación de negociar acceso soberano al mar y su supuesto incumplimiento (CIJ, 2015a, p. 14, párr. 31; CIJ, 2015b, p. 41). 
Además, la Corte reconoció que:

32. [...] las solicitudes que son sometidas a la Corte frecuentemente presentan una disputa particular que surge en el contexto de un desacuerdo más amplio entre las Partes. [...] La Corte considera que si bien puede asumirse que el acceso soberano al Océano Pacífico es, al final, el objetivo de Bolivia, debe hacerse una distinción entre ese objetivo y lo que es la disputa misma, relacionada pero separada de ese objetivo, presentada por la Solicitud, esto es, si Chile tiene una obligación de negociar un acceso soberano de Bolivia al mar y, de existir dicha obligación, si Chile la ha incumplido. La Solicitud no pide a la Corte que juzgue y declare que Bolivia tiene un derecho de acceso soberano (CIJ, 2015a, p. 14, párr. 32; CIJ, 2015b, p. 42).

Para complementar este argumento, evitando que se malinterprete, la Corte agregó que:

33. [...] Más aún, si este caso continúa al examen de los méritos, la demanda de Bolivia pondría frente a la Corte las respectivas posiciones de las Partes sobre la existencia, naturaleza y contenido de la supuesta obligación de negociar acceso soberano. Incluso asumiendo arguendo que la Corte decidiera que existe esa obligación, no sería tarea de la Corte predeterminar el resultado de cualquier negociación que tuviese lugar como consecuencia de esa obligación (CIJ, 2015a, p. 14, párr. 33; CIJ, 2015b, p. 42).

En este orden de ideas, la Corte determinó el asunto objeto de la demanda boliviana señalando lo siguiente:

34. Sobre la base del análisis anterior, la Corte concluye que el asunto objeto de la disputa es si Chile está obligado a negociar de buena fe un acceso soberano de Bolivia al Océano Pacífico y, si esa obligación existe, si Chile la ha incumplido (CIJ, 2015a, p. 14, párr. 34; CIJ, 2015b, p. 42).

Determinado el objeto de la demanda de Bolivia, la Corte pasó a analizar si tal objeto en disputa, del modo en que lo había precisado, podría o no considerarse que se encuadra en lo regulado por el artículo VI del Pacto de Bogotá. Así, la Corte señaló que:

39. Bajo el artículo VI del Pacto de Bogotá, si la Corte llegara a decidir que, dado el objeto de la disputa, tal como fue identificado por la Corte en el párrafo 34 supra, los asuntos en disputa entre las Partes son asuntos "ya resueltos por arreglo de las partes" o «regidos por acuerdos o tratados en vigencia» el 30 de abril de 1948, entonces ella carecería del requisito de jurisdicción conforme al Pacto de Bogotá para decidir el caso en el fondo. Por consiguiente, la Corte va a proceder ahora a determinar si las cuestiones en disputa son asuntos «resueltos» o «regidos» por el Tratado de Paz de 1904 (CIJ, 2015a, pp. 15-16, párr. 39; CIJ, 2015b, pp. 43-44).

Hecho el análisis antes descrito, la Corte llegó a la siguiente conclusión

50. [...] Las disposiciones del Tratado de Paz de 1904 [...] no se refieren expresa ni implícitamente a la cuestión relativa a la presunta obligación de Chile de negociar el acceso soberano de Bolivia al Océano Pacifico. En opinión de la Corte, por lo tanto, 
los asuntos en disputa son asuntos que no se encuentran «resueltos por arreglo de las partes, o por laudo arbitral, o por sentencia de un tribunal internacional» ni "regidos por acuerdos o tratados en vigencia en la fecha de la celebración del [Pacto de Bogotá]» en el sentido que establece el artículo VI del Pacto de Bogotá (CIJ, 2015a, p. 19, párr. 50; CIJ, 2015b, p. 47).

En este orden de ideas, la Corte reafirmó su capacidad para tomar una decisión con respecto a la excepción preliminar planteada por Chile, señalando lo siguiente:

53. [...] la Corte considera que conoce todos los hechos necesarios para pronunciarse sobre la excepción de Chile y que la cuestión acerca de si los asuntos en disputa son asuntos «resueltos» o «regidos» por el Tratado de Paz de 1904 puede ser respondida sin decidir la disputa, [o algunos elementos de ella,] en sus méritos [...] Por consiguiente, la Corte considera que no está impedida de fallar sobre la excepción de Chile en esta etapa (CIJ, 2015a, p. 19, párr. 53; CIJ, 2015b, p. 48)99.

Finalmente, la decisión de la Corte fue la siguiente:

54. Teniendo en consideración el asunto objeto de la disputa, como fue identificada anteriormente (ver parágrafo 34 arriba), la Corte concluye que los asuntos en disputa no son asuntos «resueltos por arreglo de las partes, o por laudo arbitral, o por sentencia de un tribunal internacional» o «regidos por acuerdos o tratados en vigencia en la fecha de la celebración del [Pacto de Bogotá]». Por consiguiente, el artículo VI no excluye la jurisdicción de la Corte bajo el artículo XXXI del Pacto de Bogotá. La excepción preliminar de Chile a la jurisdicción de la Corte debe ser desestimada (CIJ, 2015a, p. 20, párr. 54; CIJ, 2015b, p. 48).

En este orden de ideas, en virtud de lo establecido en el párrafo 9 del artículo 79 del Reglamento de la CIJ, dado que la excepción preliminar presentada por Chile fue desestimada, el proceso contencioso debe continuar. Para ello, el mismo día en que se emitió la sentencia que resolvió la excepción preliminar, el 24 de setiembre de 2015, la Corte emitió una orden por medio de la cual fijó como nuevo plazo para la presentación de la contramemoria de Chile el 25 de julio de 2016.

\section{Breve comentario final}

El artículo VI del Pacto de Bogotá tiene, en efecto, la finalidad de que los Estados parte en dicho Tratado no puedan reabrir asuntos ya resueltos o regidos por acuerdos vigentes en la fecha de la adopción del Pacto, es decir, 30 de abril de 1948. Esto, evidentemente, busca dotar de seguridad jurídica a las relaciones entre los Estados americanos que son partes en el Pacto de Bogotá.

9 La modificación introducida en la traducción es propia. 
La sola idea de que los procedimientos pacíficos de solución de controversias, regulados en el citado Pacto, puedan ser utilizados para una completa revisión de la enorme cantidad de disputas que existieron entre los Estados americanos desde sus respectivas independencias, que incluso podrían estar vinculadas a temas que vienen de la época colonial, generaría una enorme inestabilidad jurídica y, además, política en el continente americano.

Sin embargo, en la tramitación de la excepción preliminar presentada por Chile, considero que la Corte Internacional de Justicia ha actuado correctamente y ha llegado a una decisión justa. Bolivia, a todas luces, quiere una salida soberana al océano Pacífico, lo que «podría» implicar una eventual modificación del Tratado de Paz de 1904. Sin embargo, el equipo jurídico boliviano en ningún momento ha cuestionado la validez de dicho Tratado de Paz ni solicitado su revisión o anulación. El Estado Plurinacional de Bolivia ha sido bastante claro en señalar que la obligación de Chile de negociar un acceso al océano Pacífico surge de una serie de acuerdos, práctica diplomática y declaraciones posteriores e independientes al Tratado de Paz de 1904.

Así, comparto la opinión de la Corte en el sentido de que, analizado el fondo del asunto, si hipotéticamente se le diera la razón a Bolivia considerándose que existe una obligación para Chile de negociar un acceso soberano al océano Pacífico en favor de Bolivia, en primer lugar habría que determinar la naturaleza y contenido de tal obligación y, en segundo lugar, la Corte no va a determinar el resultado preciso de las negociaciones que se lleven a cabo en virtud de una eventual sentencia en favor de Bolivia.

Además, en el hipotético supuesto de que la Corte falle en favor de Bolivia y las negociaciones entre dicho Estado y Chile lleven a la necesidad de modificar el Tratado de Paz de 1904, habría que notar que tal modificación surgiría de la voluntad de las partes y no de un mandato de la Corte. Dicha situación hipotética, por lo demás, sería el resultado de una obligación jurídica contraída por Chile luego de la celebración del Tratado de Paz de 1904; obligación jurídica cuya existencia y violación por parte de Chile es, precisamente, el asunto en disputa planteado por Bolivia.

En suma, es evidente que Bolivia no está solicitando la revisión o anulación del Tratado de Paz de 1904 y que, además, la Corte no puede pronunciarse sobre ello. Lo que se ha solicitado, en primer término, es la determinación de la existencia de una obligación de Chile, surgida luego de celebrado el Tratado de Paz de 1904, independientemente de él, pero evidentemente vinculada a dicho Tratado; tema respecto del cual no hay acuerdo entre las partes en disputa, lo que configura una controversia jurídica no resuelta y que, precisamente, es el asunto que Bolivia quiere ventilar en la Corte. $\mathrm{Si}$, hipotéticamente, la Corte determina que tal obligación existe y fue incumplida, el efecto que esto tenga sobre el Tratado de Paz de 1904 no sería responsabilidad 
de la Corte ni tampoco sería un tema que la Corte pueda decidir, en virtud del artículo VI del Pacto de Bogotá; sino que sería consecuencia de los acuerdos, práctica diplomática y declaraciones de los Estados involucrados, que habrían generado tal obligación.

En otras palabras, en virtud del artículo VI del Pacto de Bogotá, la Corte no puede pronunciarse sobre los temas resueltos y regidos por el Tratado de Paz de 1904, tampoco puede pronunciarse sobre la validez de dicho Tratado, pero sí puede pronunciarse sobre la existencia o no de una obligación jurídica independiente y posterior a él que, eventual e hipotéticamente, implique una modificación del Tratado de Paz de 1904, en tanto que la determinación de la existencia o no de dicha obligación sea un tema aún no resuelto por las partes en la controversia.

En este orden de ideas, si Chile presentó la excepción preliminar bajo la firme creencia de que llevaba razón y de que, por tanto, debía ser resuelta en su favor, considero que el equipo jurídico chileno no valoró de manera adecuada la situación. Sin embargo, si la excepción preliminar fue planteada como una estrategia procesal para ganar tiempo en atención a algún tipo de cálculo político interno o con miras a una mejor preparación del asunto de fondo, el equipo jurídico chileno habría logrado su objetivo.

En efecto, si consideramos que la contramemoria chilena debió originalmente presentarse el 18 de febrero de 2015 y, en virtud de la tramitación de la excepción preliminar, ahora deberá presentarse el 25 de julio de 2016, Chile habría ganado 17 meses y 4 días (casi un año y medio). Como señala Kolb:

[...] the central effect of lodging a Preliminary Objection is to 'stop the clock' - suspending proceedings on the substantive issues, so that prior and separate consideration can be given to the examination of the objections (2013, p. 224).

Para terminar, solo queda por decir que, resuelta la excepción preliminar y afirmada la competencia de la Corte para conocer este asunto, el proceso sobre el fondo se ha retomado, la fecha para la presentación de la contramemoria chilena ya fue fijada y las fechas de las posteriores actuaciones serán oportunamente determinadas por la Corte.

No quisiera aventurar una predicción sobre el posible resultado final de este asunto; solo quiero recordar que si la Corte fallare en favor de Bolivia, se llevasen a cabo negociaciones y el resultado de ellas implicara la posibilidad de otorgar un acceso soberano al océano Pacífico en favor de Bolivia por el territorio de Arica, el Perú se vería involucrado en este asunto en virtud del artículo primero del Protocolo Complementario al Tratado de Lima de 1929. En ese sentido, es labor de la Cancillería peruana estar preparada para esta eventualidad y revisar, de existir, cualquier acuerdo, práctica diplomática o declaración de los más altos representantes del Perú, que puedan tener relación con esta materia o generar algún tipo de consecuencia jurídica para el Perú. 


\section{Referencias bibliográficas}

Abi-Saab, Georges (1967). Les exceptions préliminaires dans la procédure de la Cour Internationale: Etudes des notions fondamentales de procédure et des moyens de leur mise en ouvre. París: Pedone.

Acosta Estévez, José (1995). El proceso ante el Tribunal Internacional de Justicia. Barcelona: J.M. Bosch Editor.

CIJ. Corte Internacional de Justicia (2015a). Obligation to negotiate access to the Pacific Ocean (Bolivia v. Chile). Preliminary objection. Sentencia del 24 de setiembre del 2015. Disponible en: http://www.icj-cij.org/docket/files/153/18746.pdf

CIJ. Corte Internacional de Justicia (2015b). Sentencia: Obligación de negociar una salida al océano Pacífico (Bolivia c. Chile). Excepción Preliminar. De 24 de septiembre del 2015 (Traducción no oficial). Revista Tribuna Internacional, Facultad de Derecho de la Universidad de Chile, 4(8). Disponible en: http://www.tribunainternacional. uchile.cl/index.php/RTI/article/viewFile/38177/39835. DOI: 10.5354/0719-482X. 2015.38177

CIJ. Corte Internacional de Justicia (2007). Territorial and Maritime Dispute (Nicaraguav. Colombia). Preliminary Objections. De 13 de diciembre de 2007. Reports, 2007 (II). Disponible en: http://www.icj-cij.org/docket/files/124/14305.pdf

Kolb, Robert (2013). The International Court of Justice. Oxford: Hart Publishing.

Pastro Ridruejo, José Antonio (1967). La sentencia del Tribunal de La Haya de 24 de julio de 1964: excepciones preliminares en el caso Barcelona Traction. En: Estudios sobre el Tribunal Internacional de Justicia, Zaragoza.

Fecha de recepción: 7 de marzo de 2016 Fecha de aprobación: 29 de abril de 2016 